\title{
Clustering of Obesity and Dental Health with Lifestyle Factors among Turkish and Finnish Pre-Adolescents
}

\author{
Basak Cinar Heikki Murtomaa \\ Department of Oral Public Health, Institute of Dentistry, University of Helsinki, Finland
}

\section{Key Words}

Obesity · Dental health - Lifestyle factors .

Pre-adolescents · Socio-economic status

\section{Summary}

Background: This study aims to assess any clustering between obesity, number of decayed, missing, and filled teeth (DMFT), television (TV) viewing, and lifestyle factors among pre-adolescents living in 2 countries with different developmental status and oral health care systems - Turkey and Finland. Patients and Methods: A cross-sectional study of Finnish ( $n=338$ ) and Turkish ( $n=611$ ) preadolescents, 10-12 years old, was undertaken with preadolescent oral health data and health behavior questionnaires for pre-adolescents and their mothers. The parameters examined were DMFT, body mass index (BMI), leisure time activities (TV viewing), and lifestyle factors (family dinners and dietary habits) of pre-adolescents. Data analysis included factor analysis, Student's t-test, and Chi-square tests by cross tabulation. Results: Turkish pre-adolescents were more obese and had poorer dental health than their Finnish counterparts $(p<0.05)$. Turkish and Finnish pre-adolescents drinking fizzy drinks more than 3 times a week were more likely to watch TV for $\geq 2 \mathrm{~h} / \mathrm{school}$ day (odds ratio $(\mathrm{OR})=1.51,95 \%$ confidence interval (Cl) 1.00-2.28) than those consuming them once a week or less (OR $=3.06,95 \% \mathrm{Cl} 1.39-6.75$; $\mathrm{p}<0.05)$. Factor analysis revealed that DMFT and obesity shared the same cluster among Turkish and Finnish pre-adolescents. Conclusion: Both medical and dental examination of any pediatric patient should include BMI, leisure time activities, and dietary habits as well as socio-economic status.

\section{Introduction}

Obesity and dental caries among children and adolescents are major public health concerns, described as a global pandemic $[1,2]$ due to their global distribution and severe consequences. Both have a negative impact on quality of life [3,4], and track into adulthood [5, 6]. These 2 global health problems relate to common lifestyle factors such as unhealthy eating patterns [7, 8], less frequent family dinners [9], and increased consumption of sweetened beverages among children and adolescents $[10$, 11]. These maladopted habits also track into later life as predictors of increased risk of obesity [12] and higher rates of caries [7]. Leisure time activities seem to act as mediating agents between obesity and poor lifestyle factors. Children and adolescents who watch television (TV) for longer hours are more likely to consume more sweetened beverages and snacks [13] and are therefore more likely to be obese [11]. Increased hours of TV watching seem to also expose them to higher rates of caries [14]. Child viewers are exposed to a TV environment that predominantly promotes unhealthy food high in fat, sugar, and salt, nutrients associated with obesity, dental caries, and other chronic diseases $[15,16]$. However, studies on the relationship between caries and TV viewing are scarce.

There is growing interest in the association between children's weight and dental caries [17-19], without exploration of their common contributors as yet [19]. If factors such as lifestyle and leisure time activities both affect dental caries and obesity, then dental health, growth, and general well-being of children require the active participation of both dental and general health care providers to implement obesity/dental caries prevention strategies for the young by use of a holistic perspective. The aim of the present study was - to our knowledge for the first time - to assess any clustering between obesity, dental health, TV viewing, and lifestyle factors (dietary patterns and

Ayse Basak Cina

Department of Oral Public Health

Institute of Dentistry, University of Helsinki

P.O. Box 41, 00014 Helsinki, Finland

Tel. +3584082443

basak.cinar@helsinki.fi. 


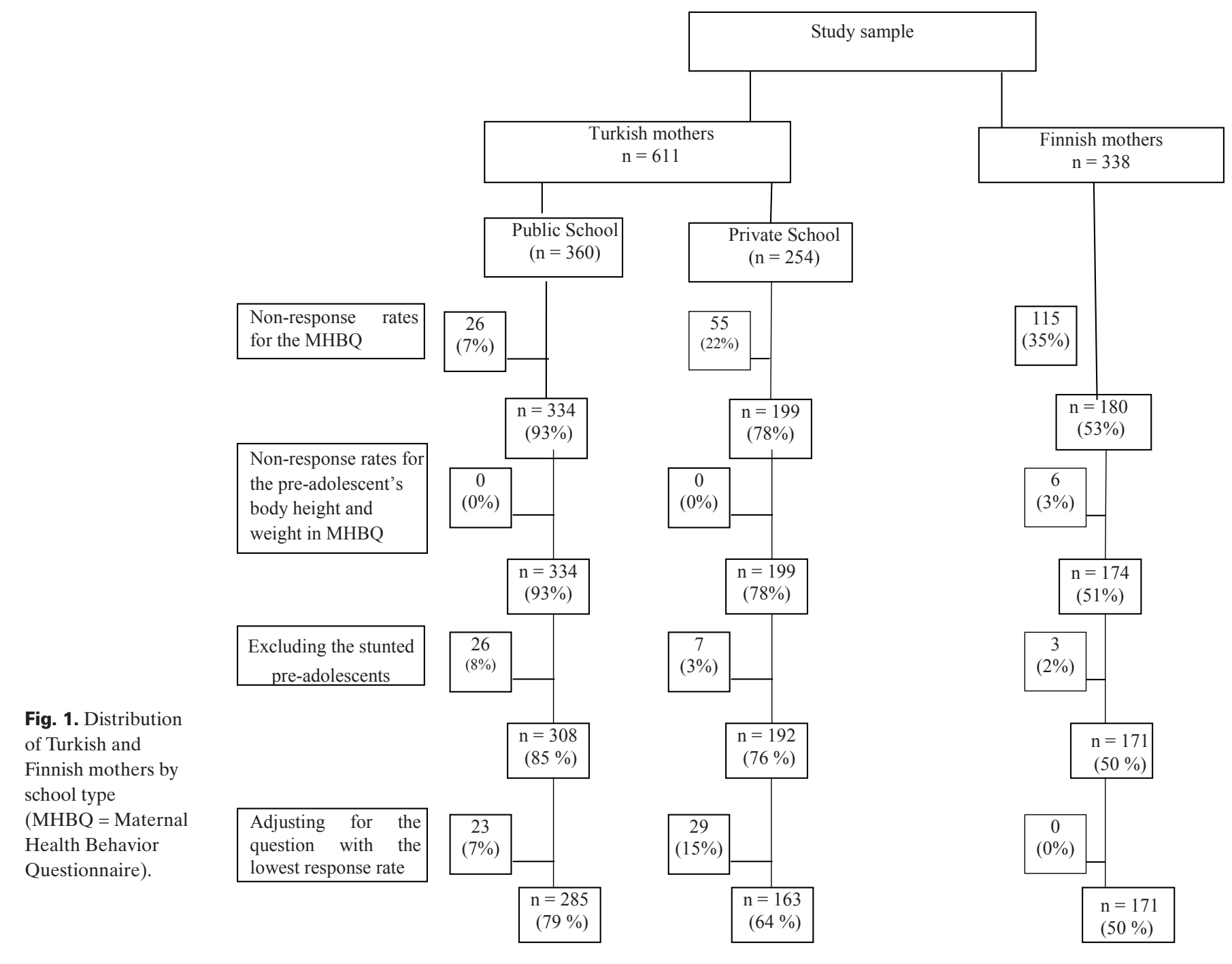

family dinners) among pre-adolescents living in 2 countries with differing economic developmental status and oral health care systems: Turkey and Finland.

\section{Material and Methods}

Study Design and Subjects

In spring 2004, a cross-sectional study of Finnish and Turkish pre-adolescents from the 4 th, 5 th, and 6 th grades, aged $10-12$ years, was undertaken with questionnaires for pre-adolescents and their mothers, and pre-adolescent oral health data, in Munkkiniemi, a suburb of Helsinki $(\mathrm{n}=338)$, and Kadiköy, a managerial district of Istanbul $(\mathrm{n}=611)$. In Turkey, 2 schools were selected by cluster sampling from high and low socio-economic suburbs to represent the general profile of the Kadiköy district. In Turkey, child education is based on individual fees ranging from low to high in public and private schools, respectively, representing families' low or high socio-economic profile. The representativeness of public and private school for socio-economic status in the present study was described previously [20]. In Finland, 2 primary schools were chosen at random to represent pre-adolescents living in Helsinki; no distinct differences existed in socio-economic profiles. The sample selection was also described previously [20].

Self-administered health behavior questionnaires meant for these preadolescents and their mothers were revised after testing in a pilot study in 2003 on a sample of 4th-grade elementary school pre-adolescents $(n=63)$ in Istanbul [20]. The Turkish response rate was $95 \%$ for the clinical examinations $(\mathrm{n}=552 ; 332$ public and 220 private school pre-adolescents), $97 \%$ for the health behavior questionnaire for pre-adolescents $(n=591 ; 345$ public and 246 private schools), and $87 \%$ for that of the mothers ( $\mathrm{n}=533$; 334 public and 199 private schools). The Finnish clinical examination rate was $65 \%$. Finnish data showed a response rate for pre-adolescents of $65 \%$ $(\mathrm{n}=221)$, and for their mothers $53 \%(\mathrm{n}=180)$. Boys comprised $51 \%$ of the Turkish and $57 \%$ of the Finnish population. Ethical approval and written permission were granted to conduct the study, and written informed consent was provided by all the participating mothers and pre-adolescents [20]. Two native speakers translated the questionnaires from English into Turkish and into Finnish to ensure accuracy compared with the original forms in English. The pre-adolescent health behavior questionnaires were completed during class, whereas those for mothers were taken home and returned by the pre-adolescents during the following 2 weeks.

\section{Clinical Examinations}

The number of decayed, missing, and filled permanent primary teeth (DMFT) in pre-adolescents was measured by clinical examinations in Turkey and Finland, based on World Health Organization (WHO) criteria [21]. In Finland, children under 18 years of age are entitled to comprehen- 
Table1. Characteristics of Turkish and Finnish pre-adolescents by gender

\begin{tabular}{|c|c|c|c|c|c|c|c|c|}
\hline \multirow[t]{2}{*}{ Characteristics } & \multicolumn{4}{|c|}{ Turkish pre-adolescents } & \multicolumn{4}{|c|}{ Finnish pre-adolescents } \\
\hline & $\begin{array}{l}\text { total } \\
(\mathrm{n}=448) \\
\text { mean }(\mathrm{SD})\end{array}$ & $\begin{array}{l}\text { boys } \\
(\mathrm{n}=228) \\
\text { mean }(\mathrm{SD})\end{array}$ & $\begin{array}{l}\text { girls } \\
(\mathrm{n}=220) \\
\text { mean }(\mathrm{SD})\end{array}$ & $\mathrm{p}$ value & $\begin{array}{l}\text { total } \\
(\mathrm{n}=171) \\
\text { mean }(\mathrm{SD})\end{array}$ & $\begin{array}{l}\text { boys } \\
(\mathrm{n}=96) \\
\text { mean }(\mathrm{SD})\end{array}$ & $\begin{array}{l}\text { girls } \\
(\mathrm{n}=75) \\
\text { mean }(\mathrm{SD})\end{array}$ & $\mathrm{p}$ value \\
\hline Age, years & $\begin{array}{l}10.89 \\
(0.78)\end{array}$ & $\begin{array}{l}10.92 \\
(0.79)\end{array}$ & $\begin{array}{l}10.85 \\
(0.78)\end{array}$ & NS & $\begin{array}{l}11.25 \\
(0.74)\end{array}$ & $\begin{array}{l}11.23 \\
(0.71)\end{array}$ & $\begin{array}{l}11.27 \\
(0.78)\end{array}$ & NS \\
\hline Height, $\mathrm{cm}$ & $\begin{array}{l}142.8 \\
(9.76)\end{array}$ & $\begin{array}{l}142.8 \\
(9.83)\end{array}$ & $\begin{array}{l}142.7 \\
(9.70)\end{array}$ & NS & $\begin{array}{l}150.8 \\
(10.04)\end{array}$ & $\begin{array}{l}150.0 \\
(8.39)\end{array}$ & $\begin{array}{l}151.8 \\
(11.8)\end{array}$ & NS \\
\hline Weight, kg & $\begin{array}{l}38.3 \\
(8.72)\end{array}$ & $\begin{array}{l}39.3 \\
(9.21)\end{array}$ & $\begin{array}{l}37.2 \\
(8.06)\end{array}$ & 0.009 & $\begin{array}{l}42.12 \\
(9.11)\end{array}$ & $\begin{array}{l}41.44 \\
(9.89)\end{array}$ & $\begin{array}{l}42.9 \\
(7.99)\end{array}$ & NS \\
\hline $\mathrm{BMI}, \mathrm{kg} / \mathrm{m}^{2}$ & $\begin{array}{l}18.65 \\
(2.91)\end{array}$ & $\begin{array}{l}19.1 \\
(2.95)\end{array}$ & $\begin{array}{l}18.1 \\
(2.80)\end{array}$ & 0.001 & $\begin{array}{l}18.38 \\
(2.73)\end{array}$ & $\begin{array}{l}18.26 \\
(3.13)\end{array}$ & $\begin{array}{l}18.54 \\
(2.10)\end{array}$ & NS \\
\hline DMFT & $\begin{array}{l}2.93 \\
(1.99)\end{array}$ & $\begin{array}{l}2.72 \\
(1.88)\end{array}$ & $\begin{array}{l}3.13 \\
(2.08)\end{array}$ & 0.032 & $\begin{array}{l}0.71 \\
(1.54)\end{array}$ & $\begin{array}{l}0.44 \\
(1.21)\end{array}$ & $\begin{array}{l}1.05 \\
(1.83)\end{array}$ & 0.014 \\
\hline
\end{tabular}

NS $=$ Not statistically significant $(\mathrm{p}>0.05), \mathrm{SD}=$ standard deviation.

$†$ Student's t-test. sive regular oral health care free of charge, and their dental health records are regularly collected by dentists in the municipal public health centers. Each dentist follows detailed guidelines and treatment decisions outlined by the Helsinki City Health Department according to WHO criteria [21]. For this study, oral health data of Finnish pre-adolescents were taken with permission from the records stored at the Helsinki City Health Department.

The clinical examinations in Turkey were carried out in the classrooms 2 weeks before the survey by 2 calibrated pediatric dentists who worked professionally in dental university clinics. The dental examinations, based on WHO recommendations [21], were performed under field conditions using natural light. The pre-adolescent was seated in a chair with a high backrest; the examiner stood in front of the chair. Plane mouth mirrors and blunt dental probes were used for the examination. Following WHO recommendations, the examiners first recorded caries on dental charts, in terms of DMFT. Those scores for each pre-adolescent were calculated, and lesions were recorded as present when a carious cavity was detected on manual inspection. Of the study group, $10 \%$ were re-examined for inter-examiner (0.89) and intra-examiner reliability (0.96 and 0.92) of DMFT, respectively $(\mathrm{p}<0.05)$. DMFT of both groups were dichotomized into healthy (DMFT $=0$ ), and diseased (DMFT $>0$ ) subgroups for further analysis.

\section{Leisure-Time Activity, Lifestyle Factors, and Body Mass Index}

These following variables were extracted from the pre-adolescent health behavior questionnaire [20]: leisure time activities; time spent watching $\mathrm{TV}$ per school day: less than $2 \mathrm{~h}$ (favorable $=1$ ), at least $2 \mathrm{~h}$ or more (unfavorable $=0$ ) based on a study by Giammattei et al. [11]; regularity of family dinners (all family members usually eat dinner together); daily snacking on fruits between meals: yes (favorable $=1)$, no (unfavorable = $0)$. The maternal health behavior questionnaire [20] included: consumption of fast food (hamburgers/pizza and French fries), and fizzy drinks by pre-adolescents per week: 'once a week or less' and ' $2-3$ times a week or less', respectively (favorable $=1$ ), and 'more frequently' (unfavorable $=0$ ), based on the recommendations of the Food Pyramid Guidelines [22]; body mass index (BMI): mothers were asked to measure weight to the nearest $0.1 \mathrm{~kg}$, and height to the nearest $0.1 \mathrm{~cm}$ with the pre-adolescents wearing only their underwear and footwear, and standing erect against a wall-mounted measuring tape. Parents were asked not to include any earlier measurements available, and to take new measurements after the arrival of the questionnaires at home. Of the Turkish study group, $10 \%$ of mothers were asked to complete again the maternal health behavior questionnaires 2 weeks after cessation of the survey for the measurement of intra-examiner reliability which was 0.78 for height, and 0.74 for weight $(\mathrm{p}<0.05)$.

BMI-for-age percentiles (weight in $\mathrm{kg} /$ height in $\mathrm{m}^{2}$ ), developed and used as a growth and nutrition reference by WHO, are dependent on genderand age-specific weight for height charts for ages 5-19 years [23]. According to these charts, 'non-obese', 'at risk for overweight', and 'overweight' were defined, respectively, as 5th percentile $<$ BMI-for-age $<85$ th percentile, 85 th percentile $<$ BMI-for-age $<95$ th percentile, and BMI-for-age $>95$ th percentile [18]. The frequency distribution of 'underweight/ undernutrition', defined as BMI-for-age $<5$ th percentile [24], was small among both Turkish (public and private school pre-adolescents: $\mathrm{n}=26(8 \%)$ and $\mathrm{n}=7(3 \%)$, respectively; $\mathrm{p}<0.05)$ and Finnish $(\mathrm{n}=3(2 \%))$ pre-adolescents, and was extracted from further data analysis in order to compare non-obese and obese pre-adolescents. The pre-adolescents 'at risk for overweight' and 'overweight' were assigned to the 'obese' group [19]. After extracting stunted pre-adolescents from the data, further statistical analysis was performed according to the question with the lowest response rate, time spent watching TV per school day (Turkish public and private school pre-adolescents: $\mathrm{n}=285$ and $\mathrm{n}=163$, respectively; Finnish: $\mathrm{n}=171$ ) (fig. 1).

\section{Statistical Methods}

Factor analysis was applied to these variables by using principal component analysis and Varimax rotation to analyze the interrelationships and common underlying dimensions among dental health, obesity, and lifestyle factors by classifying these variables into discriminative clusters based on their factorial loadings, ranging from highest to lowest values, among Turkish and Finnish pre-adolescents. Factors were extracted according to meeting the Kaiser criterion of eigenvalue greater than 1. Descriptive statistics, frequency distributions, the contingency coefficient for determining associations between variables, and binary logistic regression were applied. In addition, Chi-square tests by cross-tabulation were applied to compare frequencies, and the corresponding odds ratios (OR) were calculated. Statistical significance was set at $\mathrm{p}<0.05$.

\section{Results}

\section{Dental Health And BMI Measures}

Characteristics of Turkish and Finnish pre-adolescents are shown in table 1. Mean BMI of Turkish pre-adolescents was 
Table 2. TV viewing, and lifestyle measures of Turkish and Finnish preadolescents

\begin{tabular}{|c|c|c|c|c|c|c|}
\hline & \multicolumn{4}{|c|}{ Turkish pre-adolescents, \% } & \multirow{2}{*}{$\begin{array}{l}\text { Finnish pre- } \\
\text { adolescents, } \\
\%(\mathrm{n}=171)\end{array}$} & \multirow[t]{2}{*}{$\mathrm{p}$ value ${ }^{\mathrm{a}}$} \\
\hline & $\begin{array}{l}\text { public school } \\
(\mathrm{n}=285)\end{array}$ & $\begin{array}{l}\text { private school } \\
(\mathrm{n}=163)\end{array}$ & $\begin{array}{l}\text { total } \\
(\mathrm{n}=448)\end{array}$ & $\mathrm{p}$ value & & \\
\hline \multicolumn{7}{|c|}{ TV viewing on a school day } \\
\hline Favorable & 67 & 77 & 72 & 0.005 & 85 & 0.001 \\
\hline Unfavorable & 33 & 22 & 28 & & 15 & \\
\hline \multicolumn{7}{|c|}{ Dinner with family members } \\
\hline Favorable & 89 & 68 & 81 & 0.001 & 61 & 0.001 \\
\hline Unfavorable & 11 & 32 & 19 & & 39 & \\
\hline \multicolumn{7}{|c|}{ Fizzy drinks per week } \\
\hline Favorable & 74 & 78 & 76 & NS & 84 & 0.019 \\
\hline Unfavorable & 26 & 22 & 24 & & 16 & \\
\hline \multicolumn{7}{|c|}{ Fast food per week } \\
\hline Favorable & 71 & 77 & 74 & NS & 89 & 0.001 \\
\hline Unfavorable & 29 & 22 & 26 & & 11 & \\
\hline \multicolumn{7}{|c|}{ Daily snacking on fruits between meals } \\
\hline Favorable & 49 & 63 & 55 & 0.001 & 40 & 0.002 \\
\hline Unfavorable & 51 & 37 & 45 & & 60 & \\
\hline
\end{tabular}

NS = Not statistically significant $(\mathrm{p}>0.05)$.

${ }^{\text {aS }}$ Statistical difference between Turkish (total) and Finnish pre-adolescents.

$\dagger$ Chi-squared test. similar to that of the Finnish ( $p>0.05)$. Mean values of DMFT were higher among Turkish pre-adolescents than among the Finnish $(\mathrm{p}<0.05)($ table 1$)$. Turkish pre-adolescents attending public school had lower mean BMI (17.88 \pm 3.01$)$ but higher mean DMFT $(3.28 \pm 1.81)$ than their counterparts in private school $(18.98 \pm 3.01,2.46 \pm 2.22 ; \mathrm{p}<0.001)$.

Turkish pre-adolescents were more obese (28\%, BMI-for-age $\geq 85$ th percentile) and had poorer dental health (84\%, DMFT $>0)$ than were the Finnish $(20 \%, 33 \%$; $<0.05)$. Turkish public school pre-adolescents, compared to their counterparts in private school, were less obese ( 22 vs. $39 \%$ ), but had more dental health problems (92 vs. $73 \%)(\mathrm{p}<0.001)$. No association appeared between obesity and dental disease among both Turkish and Finnish pre-adolescents (logistic regression; unadjusted $p>0.05$, adjusted for lifestyle factors and leisure time activities $p>0.05)$. Similarly non-significant differences appeared between Turkish public and private school pre-adolescents (logistic regression; unadjusted $\mathrm{p}>0.05$, adjusted for lifestyle factors and leisure time activities $\mathrm{p}>0.05$ ).

\section{Lifestyle Factors and Leisure Time Activities}

Finnish pre-adolescents were less likely to snack on fruits (OR $=0.61,95 \%$ confidence interval $(\mathrm{CI}) 0.45-0.84 ; \mathrm{p}=0.001)$ than were their Turkish counterparts (table 2). Turkish pre-adolescents eating fast food more than once a week were more likely to watch TV $(36 \%, 2 \mathrm{~h}$ or more/school day) (OR $=1.60$, 95\% CI 1.04-2.46) and to eat dinners separate from their families ( $44 \%$, OR $=2.15,95 \%$ CI $1.32-3.50)$ than were those con- suming fast food once a week or less $(26 \%, 27 \%$; $<<0.05)$. A similar association appeared between increased TV viewing on a school day and drinking fizzy drinks more than 3 times a week among Turkish $(\mathrm{OR}=1.51,95 \%$ CI $1.00-2.28 ; \mathrm{p}=0.051)$ and Finnish pre-adolescents (OR $=3.06,95 \%$ CI 1.39-6.75; $\mathrm{p}=0.009)$. Turkish private school pre-adolescents were more likely to eat dinner separately $(89 \%, \mathrm{OR}=3.87,95 \% \mathrm{CI}$ 2.47-6.06) and to have decreased TV viewing (33\%, OR = $1.24,95 \%$ CI 1.08-1.43) than did their public school counterparts $(68 \%, 22 \% ; \mathrm{p}<0.05)($ table 2$)$. Both private and public school pre-adolescents eating fast food more than once a week were more likely to drink fizzy drinks more than 3 times a week $(96 \%, \mathrm{OR}=96,95 \%$ CI $24.1-381.1$ and $89 \%$, OR $=23.0$, 95\% CI 12.9-40.9, respectively) than were those consuming it once a week or less $(0 \%, 0 \% ; p<0.01)$.

\section{Clustering between DMFT and BMI}

Principal component analysis revealed that DMFT was the common contributor to obesity among Turkish and Finnish pre-adolescents (table 3 ).

\section{Discussion}

Investigation of the interrelation between DMFT and obesity in school-aged children has been controversial. Willerhausen et al. [17] found a positive correlation between high DMFT and obesity, whereas Macek et al. [18] described an inverse re- 
Table 3. Factor analysis for assessing behavioral clusters of DMFT (dentally healthy vs. diseased) and BMI (obese vs. non-obese) among Turkish preadolescents and their Finnish counterparts by Varimax rotated solution (all behavioral variables, i.e. dietary habits and television viewing, classified as favorable (1) and unfavorable (0) along with health measures (dentally healthy $=1$, non-obese $=1$ )). The clusters in 3 study groups, in total, accounted for $58.8,62.6$, and $38.9 \%$ of the total variance.

\begin{tabular}{|c|c|c|c|c|c|c|c|c|}
\hline & \multicolumn{3}{|c|}{$\begin{array}{l}\text { Turkish public school pre-adolescents } \\
(\mathrm{n}=285)\end{array}$} & \multicolumn{3}{|c|}{$\begin{array}{l}\text { Turkish private school pre-adolescents } \\
(\mathrm{n}=163)\end{array}$} & \multicolumn{2}{|c|}{$\begin{array}{l}\text { Finnish pre-adolescents } \\
(\mathrm{n}=171)\end{array}$} \\
\hline & health & $\begin{array}{l}\text { leisure time } \\
\text { activity }\end{array}$ & $\begin{array}{l}\text { diet-related } \\
\text { behavior }\end{array}$ & health & $\begin{array}{l}\text { leisure time } \\
\text { activity }\end{array}$ & $\begin{array}{l}\text { diet-related } \\
\text { behavior }\end{array}$ & health & $\begin{array}{l}\text { diet-related } \\
\text { behavior }\end{array}$ \\
\hline DMFT & 0.814 & 0.356 & $*$ & 0.566 & 0.396 & $*$ & 0.598 & $*$ \\
\hline BMI & -0.605 & $*$ & $*$ & 0.560 & $*$ & $*$ & 0.369 & $*$ \\
\hline TV viewing on a school day & $*$ & 0.550 & $*$ & $*$ & 0.730 & $*$ & 0.355 & 0.554 \\
\hline Dinner with family members & $*$ & 0.282 & $*$ & 0.681 & $*$ & 0.313 & 0.499 & 0.294 \\
\hline Fizzy drinks per week & * & $*$ & 0.972 & $*$ & * & 0.978 & $*$ & 0.758 \\
\hline Fast foods per week & * & $*$ & 0.970 & $*$ & $*$ & 0.977 & * & 0.640 \\
\hline $\begin{array}{l}\text { Daily snacking on fruits } \\
\text { between meals }\end{array}$ & * & 0.759 & $*$ & $*$ & 0.704 & $*$ & 0.608 & $*$ \\
\hline
\end{tabular}

*Factor loadings below 0.25 extracted for ease of communication.

lationship. In contrast, Pinto et al. [19] found no association. The nature of this association among school-aged children is therefore still obscure, as no other factors influencing it have been measured [19]. No association appeared between DMFT and obesity among Turkish and Finnish pre-adolescents, in line with the earlier finding [19], but the clustering of these 2 parameters among all pre-adolescents may indicate that obesity and DMFT share some underlying factors, regardless of nationality, socio-economic differences, and differing oral health care systems.

The reverse clustering between dental disease (DMFT $>0$ ) and obesity (BMI-for-age $\geq 85$ th percentile) among Turkish public school pre-adolescents may underlie one type of malnutrition, undernutrition, which is defined by WHO as 'food intake that is continuously insufficient to meet dietary energy requirements' [25]. Dental caries and its consequences dental pain and chronic inflammation restrict the quantity and variety of food eaten [26], leading to inadequate food intake and undernutrition and therefore to decreased growth (BMI-forage) among children and adolescents [27]. Undernutrition has been found to be more common among children from deprived families [28]. Acs et al. [27, 29] found that young children with high levels of untreated caries are lower in BMIfor-age but catch up to their ideal BMI-for-age after dental treatment [29]. In line with these studies, our Turkish public school pre-adolescents had higher levels of undernutrition and dental disease, and had a lower BMI than their counterparts in private school. In the light of studies by Acs et al. [27,29] and Popkin et al. [30], it may be proposed that even though public school pre-adolescents were more likely to be non-obese than their private school counterparts, they may be at risk for 'hidden' obesity; if their diet and dental health improve, they are at increased risk for becoming obese.
Among Turkish private school and Finnish pre-adolescents, the direct clustering between dental disease and obesity along with 'family dinners eaten separately' may be a sign of overnutrition. Overnutrition, another type of malnutrition, is defined as 'a chronic condition where intake of food is in excess of dietary energy requirements by overconsumption of energy-dense, nutrient-poor foods (high in fats and sugars and not enough nutrients), and leisure time activities' [25]. Children not eating regular family dinners are more likely to consume energy-dense, nutrient-poor foods [31], and to be obese [9]. Further, having family dinners together means more leisure time spent together and allows parents to regulate their children's eating behavior and attitudes, and it reduces the time spent on and hazardous effects of watching too much TV [9], thus promoting better dental health $[14,16]$. Among Finnish pre-adolescents, less TV viewing was clustered positively with consumption of less unhealthy food, in line with earlier studies [13], and 'family dinners eaten separately' contributed to this clustering. This is in line with the study by Haapalahti et al. [32] that Finnish pre-adolescents eating regular family dinners were more likely to consume healthy foods.

A similar protective effect of less TV viewing on positive dietary behaviors was observable among all Turkish pre-adolescents in terms of its contribution to daily snacking on fruits. All Turkish pre-adolescents who were more likely to watch fewer hours of TV snacked more frequently on fruits between meals, most probably due to cultural habits. In Turkey, it is traditional in families to serve fruits after dinner and to regulate the time spent on TV viewing by their children. Among OECD countries, Turkey is the second highest for fruit and vegetable consumption [33], and this may reflect the dietary habits of Turkish families. It has been reported that Turkish children imitate parental TV viewing habits, regardless of 
socio-economic differences [34]. Further, these family interaction patterns in terms of dietary habits and TV viewing seemed to contribute positively to the dental health of Turkish pre-adolescents, in line with earlier findings $[10,16]$.

Although measurement of BMI by self-report may possibly be biased, parent-reported body measurements for adolescents have been reliable and valid [35]. Assignment of Turkish and Finnish pre-adolescents to non-obese and obese groups was based on quite recently developed and published WHO international growth charts [23], and therefore the classification was standardized. In both countries, dental health data were collected by use of WHO standardized recording criteria [21]. The recording criteria have proven to be a valuable epidemiological tool, since the criteria for assessment of dental health status are practical and reliable under field conditions [21]. The use of such criteria facilitates other comparisons such as the study performed between Denmark and Estonia - one country with and the other without a national dental data bank [36]. Due to the low caries prevalence in Finland, it is doubtful that separate clinical examinations would have yielded more reliable information regarding the present dental health status. The main concern of this study was to assess the clustering between obesity, dental health, and lifestyle factors separately for Turkish and Finnish pre-adolescents and not to compare these 2 countries in terms of explanatory factors for obesity. Therefore, possible small differences in measuring dental health do not contribute as significant confounding factors. The separate clustering of snacking on fruits and unhealthy food consumption (fizzy drinks and fast food), regardless of nationality, may reveal the differing characteristics of these behaviors, as already found by Aaro et al. [37] and classified by the terms health-enhancing and -detrimental behaviors. The limitation of this study is that pubertal stages of the pre-adolescents were not assessed. New scientific evidence shows that childhood obesity induces early puberty [38]. On the other hand, puberty can result in increased probability of higher BMI [39] and DMFT [40], due to physiological changes during this stage. Therefore, in the present study, the clustering between obesity and dental caries may also underlie the fact that pre-adolescents suffering from obesity and dental disease experience early puberty or regular puberty as a common risk factor. There seems to be a need for follow-up studies considering both the general and dental health of pre-adolescents starting from childhood to identify and improve their health status.

\section{Conclusion}

Current research underlines the fact that children with high levels of dental disease - especially in developing nations with a range of socio-economic profiles - should be studied based on stratification by these profiles, because the negative consequences of higher caries rates among children with low socioeconomic status may lead to undernutrition and foretell an increased risk for obesity. Among children of better socio-economic status, both in developing and developed nations, poor dental health seems to indicate overnutrition. DMFT may be interpreted as a proxy for energy intake, in line with the earlier studies [41,42], revealing that energy intake might be more important than energy expenditure. Regardless of socio-economic and cultural differences, economic developmental status, and countries' differing oral health care systems, family interaction patterns, in terms of family dinners and TV viewing habits, seem to have a positive effect on the dietary habits and dental health of pre-adolescents; these therefore may also affect obesity patterns. As a conclusion, both medical and dental examinations of any pediatric patient should include BMI, leisure time activities, and dietary habits of pre-adolescents as well as socio-economic status. Further, the pre-adolescents' general and dental health should be supported by holistic health promotion strategies, including the empowerment of families to adopt healthy lifestyles, both in economically developing and developed countries.

\section{References}

1 Edelstein BL: The dental caries pandemic and disparities problem. BMC Oral Health 2006;6(suppl 1):S2.

2 Larson NI, Story M: The pandemic of obesity among children and adolescents: what actions are needed to reverse current trends? J Adolesc Health 2007;41:521-522.

3 Do LG, Spencer A: Oral health-related quality of life of children by dental caries and fluorosis experience. J Public Health Dent 2007;67:132-139.

4 Friedlander SL, Larkin EK, Rosen CL, Palermo TM, Redline S: Decreased quality of life associated with obesity in school-aged children. Arch Pediatr Adolesc Med 2003;157:1206-1211.

5 David J, Raadal M, Wang NJ, Strand GV: Caries increment and prediction from 12 to 18 years of age: a follow-up study. Eur Arch Paediatr Dent 2006; 7:31-37.
6 Shumei SG, William CC: Tracking of body mass index in children in relation to overweight in adulthood. Am J Clin Nutr 1999;70:145S-148S.

7 Bruno-Ambrosius K, Swanholm G, Twetman S: Eating habits, smoking and toothbrushing in relation to dental caries: a 3-year study in Swedish female teenagers. Int J Paediatr Dent 2005;15: 190-196.

8 Neutzling MB, Taddei JA, Gigante DP: Risk factors of obesity among Brazilian adolescents: a case-control study. Public Health Nutr 2003;6:743-749.

9 Gable S, Chang Y, Krull JL: Television watching and frequency of family meals are predictive of overweight onset and persistence in a national sample of school-aged children. J Am Diet Assoc 2007; 107:53-61.
10 Levine RS, Nugent ZJ, Rudolf MC, Sahota P: Dietary patterns, toothbrushing habits and caries experience of schoolchildren in West Yorkshire, England. Community Dent Health 2007;24:82-87.

11 Giammattei J, Blix G, Marshak HH, Wollitzer AO, Pettitt DJ: Television watching and soft drink consumption: associations with obesity in 11- to 13-year-old school children. Arch Pediatr Adolesc Med 2003;157:882-886.

12 Viner RM, Cole TJ: Who changes body mass between adolescence and adulthood? Factors predicting change in BMI between 16 year and 30 years in the 1970 British Birth Cohort. Int J Obes 2006;30: 1368-1374.

13 Salmon J, Campbell KJ, Crawford DA: Television viewing habits associated with obesity risk factors: a survey of Melbourne schoolchildren. Med J Aust 2006;84:64-67. 
14 Palmer CA: Dental caries and obesity in children: different problems, related causes. Quintessence 2005;36:457-461.

15 Zuppa JA, Morton H, Mehta KP: Television food advertising: counterproductive to children's health? A content analysis using the Australian Guide to Healthy Eating. Nutrition and Dietetics 2003;60: 78-84. goliath.ecnext.com/coms2/summary_0199_ 2998435_ITM.

16 Rodd HD, Patel V: Content analysis of children's television advertising in relation to dental health. Br Dent J 2005;199:710-712.

17 Willerhausen B, Blettner M, Kasaj A, Hohenfellner $\mathrm{K}$ : Association between body mass index and dental health in 1,290 children of elementary schools in a German city. Clin Oral Investig 2007;11:195-200.

18 Macek MD, Mitola DJ: Exploring the association between overweight and dental caries among US children. Pediatr Dent 2006;28:375-380.

19 Pinto A, Kim S, Wadenya R, Rosenberg H: Is there an association between weight and dental caries among pediatric patients in an urban dental school? A correlation study. J Dent Educ 2007;71: 1435-1440.

20 Cinar BA, Murtomaa HA: Comparison of psychosocial factors related to dental anxiety among Turkish and Finnish pre-adolescents. Oral Health Prev Dent 2007;5:173-179.

21 WHO: Oral Health Survey: Basic Methods, 4th ed. Geneva, World Health Organization, 1997.

22 US Department of Agriculture, US Department of Health and Human Services: Nutrition and your health: dietary guidelines for Americans, 4th ed. Washington, DC, US Government Printing Office, 1995. (Home and Garden Bulletin No. 232).

23 WHO: BMI-for-age (5-19 years). www.whoint growthref/who2007_bmi_for_agelen/index.html.

24 WHO: Physical status: the use and interpretation of anthropometry: report of a WHO Expert Committee. Geneva, World Health Organization, 1995.
25 WHO:WHO Child Growth Standards. Backgrounder 4. www.who.int/nutrition/media_page/ backgrounders_4_en.pdf.

26 Gherunpong S, Tsakos G, Sheiham A: The prevalence and severity of oral impacts on daily performances in Thai primary school children. Health Qual Life Outcomes 2004;2:57.

27 Acs G, Lodolini G, Kaminsky S, Cisneros GJ: Effect of nursing caries on body weight in a pediatric population. Pediatr Dent 1992;14:302-305.

28 Armstrong J, Dorosty AR, Reilly JJ, Emmett PM; Child Health Information Team: Coexistence of social inequalities in undernutrition and obesity in preschool children: population based cross sectional study. Arch Dis Child 2003;88:671-675.

29 Acs G, Shulman R, Ng MW, Chussid S: The effect of dental rehabilitation on the body weight of children with early childhood caries. Pediatr Dent 1999:21:109-113.

30 Popkin BM, Richards MK, Montiero CA: Stunting is associated with overweight in children of four nations that are undergoing the nutrition transition. J Nutr 1996;126:3009-3016.

31 Gillman MW, Rifas-Shiman SL, Frazier AL, Rockett HR, Camargo CA Jr, Field AE, Berkey CS, Colditz GA: Family dinner and diet quality among older children and adolescents. Arch Fam Med 2000;9:235-240.

32 Haapalahti M, Mykkänen H, Tikkanen S, Kokkonen J: Meal patterns and food use in 10- to 11-yearold Finnish children. Public Health Nutr 2003;6: 365-370.

33 Srinivasan CS, Irz X, Shankar B: An assessment of the potential consumption impacts of WHO dietary norms in OECD countries. Food Policy 2006;31: 53-77.
34 Yalçin SS, Tugrul B,Naçar N, Tuncer M, Yurdakök $\mathrm{K}$ : Factors that affect television viewing time in preschool and primary schoolchildren. Pediatr Int 2002;44:622-627.

35 Sekine M, Yamagami T, Hamanishi S, Kagamimori S: Accuracy of the estimated prevalence of childhood obesity from height and weight values reported by parents: results of the Toyama Birth Cohort study. J Epidemiol 2002;12:9-13.

36 Dragheim E, Petersen PE, Kalo I, Saag M: Dental caries in schoolchildren of an Estonian and a Danish municipality. Int J Paediatr Dent 2000;10: 271-277.

37 Aaro LE, Laberg JC, Wold B: Health behaviors among adolescents: towards a hypothesis of two dimensions. Health Educ Res 1995;10:83-93.

38 Lee JM, Appugliese D, Kaciroti N, Corwyn RF, Bradley RH, Lumeng JC: Weight status in young girls and the onset of puberty. Pediatrics 2007;119: 624-630.

39 Rogol AD, Roemmich JN, Clark PA: Growth at puberty. J Adolesc Health 2002;31(6 suppl):192-200.

40 Bruno-Ambrosius K, Yucel-Lindberg T, Twetman S: Salivary buffer capacity in relation to menarche and progesterone levels in saliva from adolescent girls: a longitudinal study. Acta Odontol Scand 2004;62:269-272.

41 Arcella D, Ottolenghi L, Polimeni A, Leclercq C: The relationship between frequency of carbohydrates intake and dental caries: a cross-sectional study in Italian teenagers. Public Health Nutr 2002; 5:553-560.

$42 \mathrm{Hu}$ WC, Ho YT, Huang ST, Chen CC, Chen HS, Hsiao SY: Relationship between obesity and oral status of children in Taiwan. J Dent Res 2004;83 (spec iss A):765. 